Corrigendum

\title{
Corrigendum to "Airmass Trajectories and Long Range Transport of Pollutants: Review of Wet Deposition Scenario in South Asia"
}

\author{
Umesh Kulshrestha and Bablu Kumar \\ School of Environmental Sciences, Jawaharlal Nehru University, New Delhi 110067, India \\ Correspondence should be addressed to Umesh Kulshrestha; umeshkulshrestha@gmail.com \\ Received 11 November 2015; Accepted 25 November 2015 \\ Copyright (C) 2016 U. Kulshrestha and B. Kumar. This is an open access article distributed under the Creative Commons Attribution \\ License, which permits unrestricted use, distribution, and reproduction in any medium, provided the original work is properly cited.
}

In the paper titled "Airmass Trajectories and Long Range Transport of Pollutants: Review of Wet Deposition Scenario in South Asia" [1] under Section 1.4 line 3, it should have been NOAA instead of NASA. The sentence should be read as follows:

"The model has been developed by NOAA."

\section{References}

[1] U. Kulshrestha and B. Kumar, "Airmass trajectories and long range transport of pollutants: review of wet deposition scenario in South Asia," Advances in Meteorology, vol. 2014, Article ID 596041, 14 pages, 2014. 

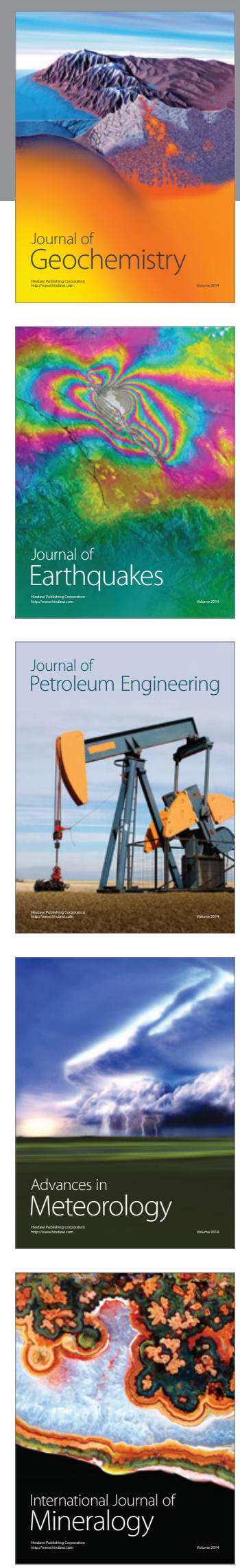
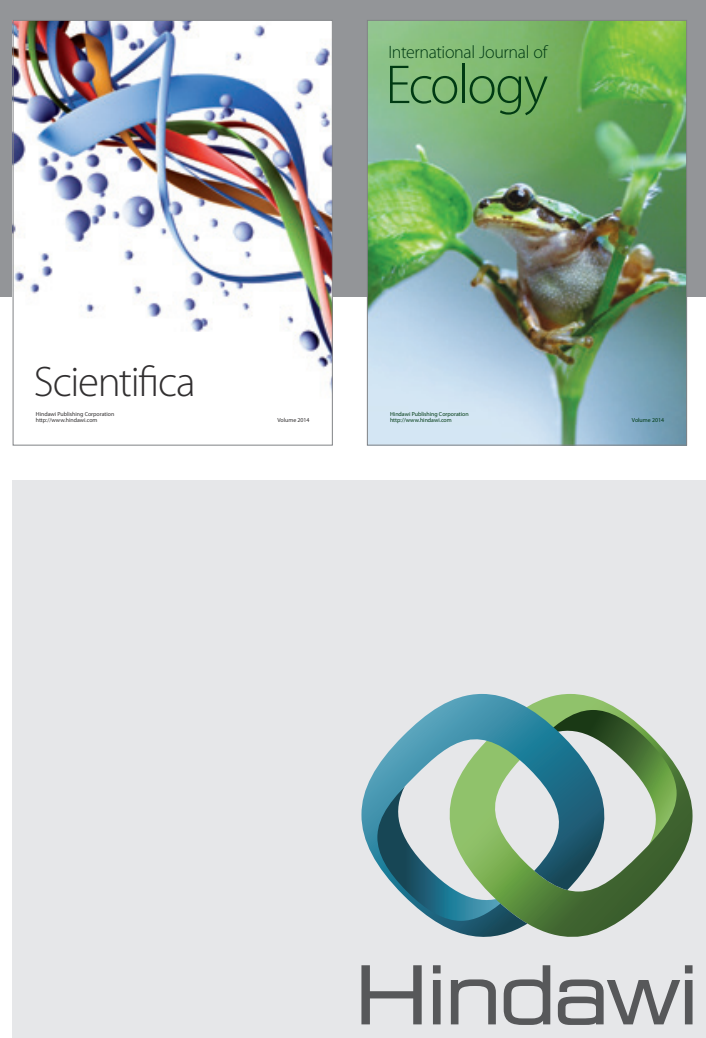

Submit your manuscripts at

http://www.hindawi.com
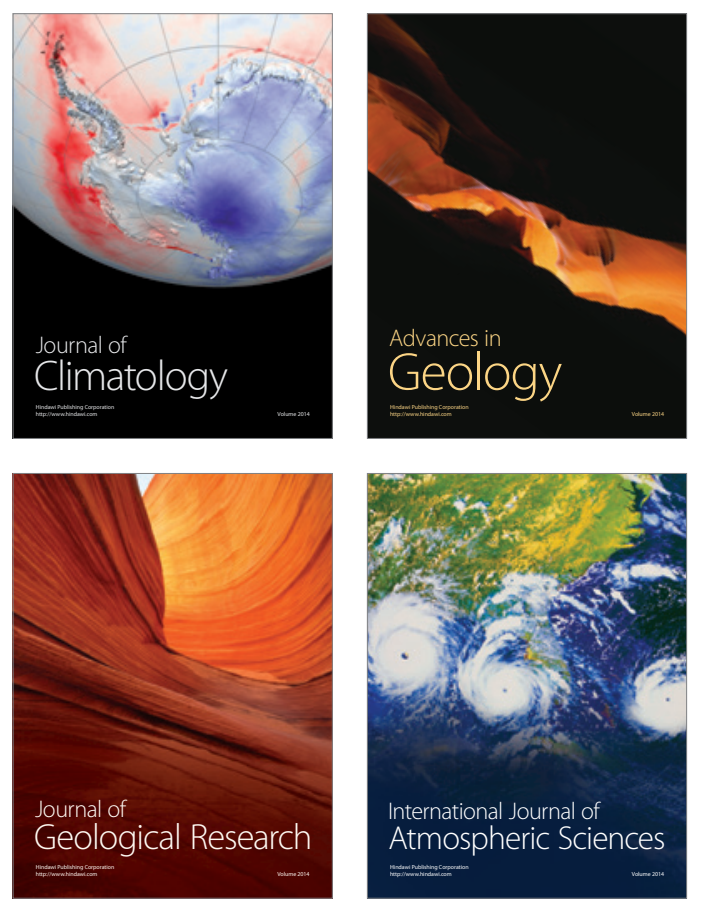

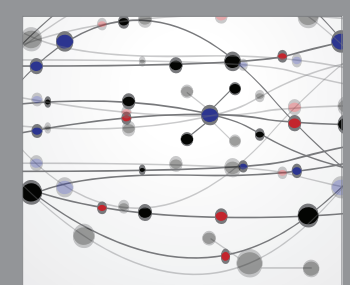

The Scientific

\section{World Journal}
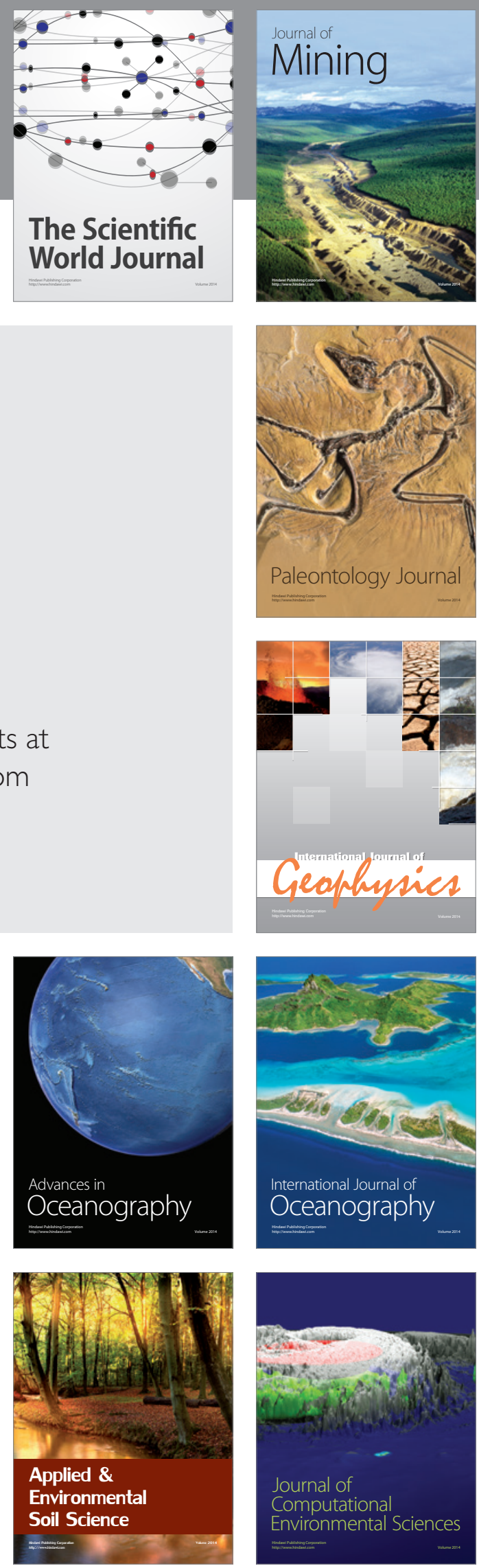